\title{
A Study on General Teaching Evaluation System Based on WEB Service for the Specialty of Industrial Designing
}

\author{
Zeng Yihui, Tang Lijun, Xiong Zhangyuan, Wang Shixiong, Yao Shi, Wu Gang \\ Anhui Wonder University Of Information Engineering, Heifei, China, 231201
}

\begin{abstract}
There exist the problems on the professional teaching of industrial design, such as lacking index pertinence, the singleness of evaluation form and method, the singleness of valuator, as well as the poor timely feedback. Therefore, this paper introduces the general teaching evaluation system based on Web service for the specialty of industrial designing so as to realize the basic function of teaching evaluation and to offer a general evaluation platform for improving teaching quality of Industrial Designing.
\end{abstract}

KEYWORD: Teaching quality; Teaching evaluation; Evaluation index; Web service

\section{GENERAL INSTRUCTIONS}

The profession of Industrial design cultivates advanced industrial designers, who majoring in cubic industrial products modeling and optical convey design, grasping the fundamental industrial design, combining knowledge and practice, The realization of cultivation aim depends on many factors. Teaching evaluation is the key way of realization of the cultivation aim. As a way of testing teaching effects, teaching evaluation is focused on teaching process, teaching design, teaching methods and teaching quality. As to the combination of special cultivation aim of Industrial Design and teaching evaluation, the traditional evaluation way, mainly by hand, on one hand, leads to the big workload and hard management; on the other hand, it is not scientific to use the evaluation results and it can't work out improvement measure by use of evaluation results with its maximum efficiency.. This teaching evaluation system based on the specialty of Industrial Design of web service is to improve the teaching quality of industrial designing profession.

\section{THE PROBLEMS ON TEACHING EVALUATION OF INDUSTURIAL DESIGNING PROFESSION}

Nowadays, the courses of industrial designing profession set up in domestic academies can be divided into three kinds: professional courses, professional theory course and professional practice course. For example, material science, technology, products structure designing and principle of machinery belong to specialized fundamental course which is becoming more and more important with the development of domestic industrial designing and the expansion of designing field. In order to realize the specialized cultivation aim in all aspects and to turn good originalities into people's life objects, the students' creative thinking, the abilities of innovating and solving problems should be cultivated. it has great importance to cultivate highqualified people majoring in industrial designing profession with innovation, application-orientation and mixed mode. How to evaluate specialized courses, specialized theory courses and specialized practice courses in a unified and effective way? Is there any possibility to develop a teaching evaluation system of general industrial designing with its index adjusted against demand, more evaluator participating, the timely feedback of evaluation results and reward, and with an evaluation index according with the cultivation aim of industrial designing? Although many scholars have been doing some research in these problems, there still exist some shortcomings:

\subsection{No pertinence of evaluation index}

Firstly, evaluation should set different index according to different specialty, and these indexes can be correspondingly adjusted and modified. The current evaluation indexes are carried out from three aspects: teachers' self-evaluation, students' evaluation of teaching, supervising expert. The 
targets of evaluation are teaching attitude, teaching method and content. However, the singleness of evaluation index content couldn't exactly reflect the real situation of teaching quality of industrial designing and the degree of students' grasping the theoretical knowledge of industrial designing. In addition, the evaluation is very subjective. Some human factors could lead to some deviations, such as knowledge experience, cognitive ability and personal preference, which makes the evaluation results accurate and complete[4]. applied evaluation index plays an key part in evaluation, which mainly reflects teaching quality of industrial designing. Therefore, constructing the application-centered evaluation index system of teaching quality has great significance.

\subsection{The singleness of evaluation form and method}

The type of organization of teaching evaluation of industrial designing profession can be divided into peer-assessment and self-assessment. Peerassessment can be divided into teachers' assessment, students' assessment and parents' assessment. In a sense, students should be the masters of evaluation. School should try to create conditions in order to make students shoulder the responsibility of evaluation. Students' evaluation can be divided into self-evaluation and mutual evaluation. Although many colleges have carried out students' evaluation, the results of students' evaluation are ignored by teachers. The evaluation methods are single, such as questionnaire survey, conversation and network evaluation, which couldn't combine the evaluation form and method well.

\subsection{The singleness of valuator}

As to the evaluation of teaching effects, it needs many valuators. Students of industrial designing are the main valuators, short of teachers, teaching leaders, supervisors, of independent evaluation organization and of businessman in relative industrial designing company. Since students' evaluations are arbitrary, the independent evaluation organization and businessman in relative industrial designing company should be introduced. Only if different evaluation results are collected can the industrial designing profession be carried out effectively.

\section{TEACHING EVALUATION SYSTEM BASED ON WEB SERVICE FOR THE SPECIALTY OF INDUSTRIAL DESIGGING}

This paper is to deal with the problems existing in teaching evaluation of industrial designing profession, based on web service platform, applying hibernate, struct and spring, and making use of $\mathrm{B} / \mathrm{S}$ system structure[6 7] which combines JSP and SQL Server 2005. Through online teaching evaluation, the modernized teaching evaluation mode can be realized. The operational principle of this system is could be diagramed as in one. The content of development is mainly about the construction and maintenance of backstage database and the development of relative foreground application program. The construction and maintenance of backstage database require the systematicness and normalization of its data while the development of the foreground application program requires the completeness of all functions, the simplicity of operation, easy learning and easy operation. The functions of this system are as follows: the relevant management of course evaluation index, the modification of evaluation course, and the comprehensive analysis of evaluation results and its check.

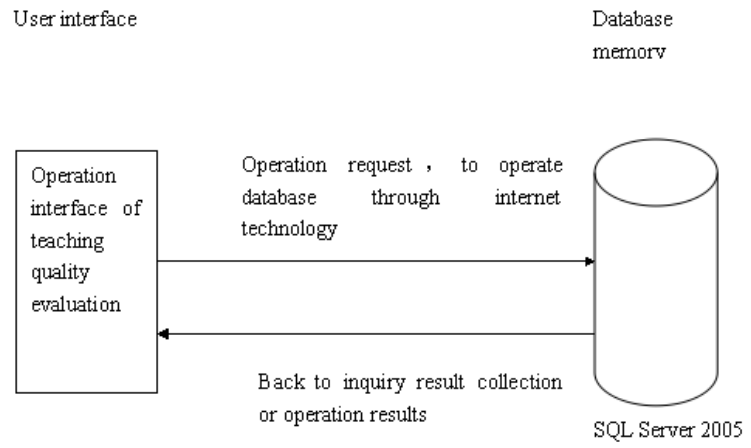

Figure 1 system working principle diagram

\subsection{The design of functional module}

The designing picture of functional module is shown in picture two. At first, before the foreground users can register and $\log$ on this system, they should register the logging on module. After entering this system, they could see the teachers to be evaluated, and then they can do this evaluation. After the backstage conservators log on, they could manage the teacher, courses and evaluation index, including adding new teachers' information and inquiring all the current teachers' information which includes the detailed evaluation results of the courses taught by corresponding teachers. The teachers' information can be modified. New evaluation indexes can be added. After finding out all the existent evaluation indexes, the relative content of these indexes can be modified. After this modification, store this new information into information database and update the old index information to keep the latest condition of these indexes. The corresponding indexes can be cancelled and modified. New course can be added, and all the existent course information can be inquired. The relevant content of these courses can be modified and corresponding indexes can be cancelled and modified as well. Different evaluation 
indexes can be allocated to different courses. The teachers can inquire their own detailed evaluation information and the average in their institutes or departments. The whole ranking of the teachers who teach the same course can be inquired. The conservators can inquire all the evaluation results of all the courses taught by corresponding teachers.

This paper is focused on the strong artistry and technicality of industrial designing profession and designs new evaluation index. The first-level indexes are knowledge, techniques and sensibility. Firstly, industrial designing projects the different knowledge of different specialties according to the teaching program. The acquisition of knowledge in class is dependent on teachers' teaching techniques and teaching design as well as the presentation modes among knowledge, etc. Most of the courses of industrial designing are involving operability. The technique index can directly reflect the degree to which students grasp the techniques. Below the firstlevel index is the second-level index. The knowledge indexes include the accuracy, scientificity, orderliness of knowledge explanation and the varieties of manifestation, etc. Technique indexes include its application, operability, understandability, imitativeness, etc. sensibility indexes include expressiveness, the right sense of worth and ethics, inter-communication, etc. The three kinds of first-level index can make teachers improve the abilities of the three: knowledge, techniques and sensibility, when they give lessons in class. The system can add, cancel and modify each index. The evaluation results can be feedback to teachers through backstage in time. According to this result, reward or punishment will be delivered to teachers. Construct and perfect a diversified evaluation system (competent department+ college +students +teachers +supervisor +a third party of evaluation +employing units +workers of companies).

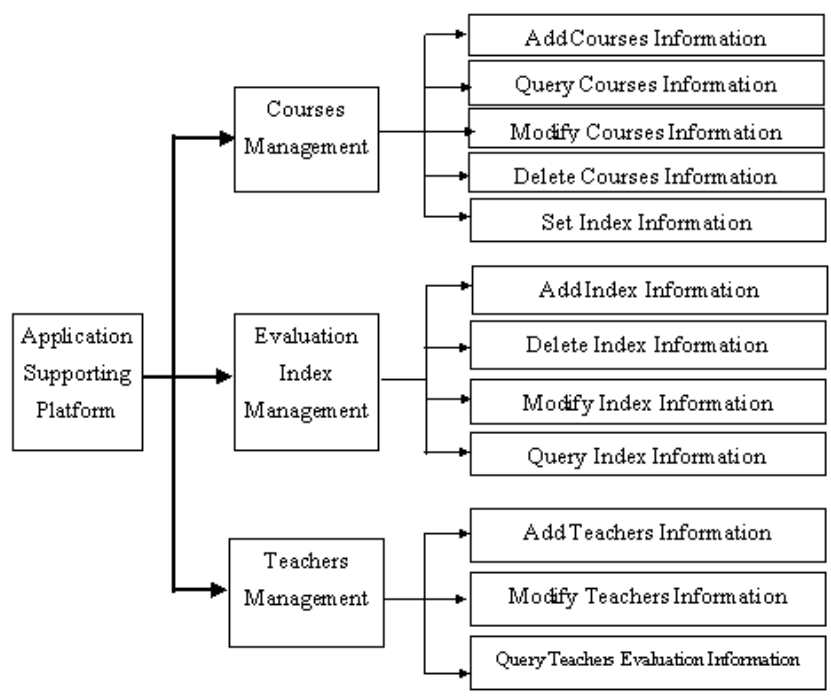

Picture 2 Teaching evaluation function

\section{2 $H$ The realization of function}

The functions of this system are as follows: the teaching qualities can be evaluated by students; conservators can insert or cancel some information of evaluation indexes; conservators can insert and cancel some information of courses; the evaluation indexes and teachers can be allocated by conservators; information about teachers can be inserted or canceled by conservators; the courses can be allocated to the teachers by conservators; evaluation results can be seen by teachers; the evaluation results of teaching quality can be seen by conservators.

The realization of evaluators' evaluation function: when students begin to enter this evaluation system, first, they should $\log$ on this system, then link database through hibernate, then verify the users' information. If some mistakes exist, back to log-on page, and re-input users' information. If no mistakes, change to the homepage of evaluation system. Users can evaluate all teachers of the courses they choose. The evaluation contents are the evaluation indexes conservators preinstall. All the evaluation indexes include knowledge, techniques and sensibility indexes. The second- level indexes can come out when spreading the first-level indexes. Meanwhile, the evaluators' comment can be submitted. Different evaluation indexes have different scores. After evaluating all indexes, users can clink the button "submit", all the data into database, and the evaluation process can be finished. After teaching evaluation, the system can send the results and advice to all the teachers.

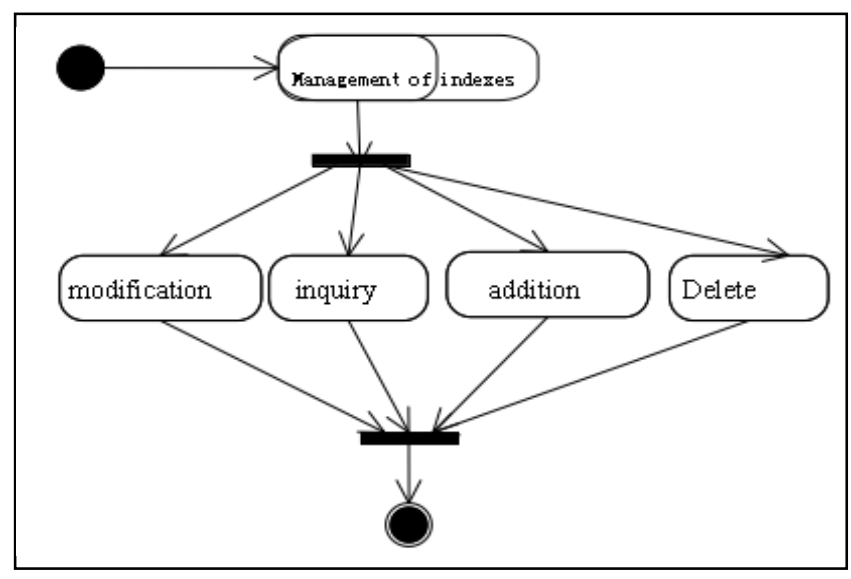

Picture 3 evaluation indexes management

The realization of index management function:

On the interface of evaluation index information, new indexes can be added, and the old indexes information can be modified or cancelled. The management module of indexes can be shown in figure 3 . In this management, knowledge, techniques and sensibility indexes can be added, or the weightiness of these indexes can be modified. 
Codes of realization as follows:

Obtain all the evaluation indexes information in function showAll() in EvaluateAction.java, then the detailed evaluation information on page showAllEvaluateItem.jsp. The codes of the function showAll() are as follows:

public ActionForward showall(ActionMapping mapping, ActionForm form,

HttpServletRequest request,

HttpServletResponse response) \{

// TODO Auto-generated method stub

String flag $=$ request.getParameter("flag");

//kinds of operation request.setAttribute("flag",flag);

//put all the targets of evaluation indexes into list

List $<$ Tevaluateitem $>$ evaluItems $=$ eservice.getAll();

//put all the evaluation information into action scope so as to get in the page

request.setAttribute("evaluItems",evaluItems);

//skip to the page of all the real evaluation indexes

return new

ActionForward("/admin/showallEvas.jsp"); \}

The modification of evaluation indexes is realized by function update() in EvaluateItem.java. This function makes the modification of evaluationindex information, the part of codes as follows:

public ActionForward update(ActionMapping mapping, ActionForm form,

HttpServletRequest request,

HttpServletResponse response) \{//obtain the

evaluation index number to be modified

int eid $=$

Integer.parseInt(request.getParameter("eid"));

//obtain the contents of evaluation index

after modificaiton

String content $=$

request.getParameter("content");

Tevaluateitem eva $=$

eservice.getEvaById(eid);

eva.setContent(content);

//renew the evaluation index

eservice.update(eva);

return new

ActionForward("/admin/success.jsp"); \}

\section{CONCLUSION}

As to the features of industrial designing profession, this paper designs three first-level indexes. The evaluators are diversified, made up of different types of people. The evaluation results can be feedback to the teachers in time, which improves the evaluaiton efficiency of industrial designing profession, and improves the teaching quality of this profession. It provides a general teaching evaluation system for realization of talents training goals of industrial designing profession.

\section{ACKNOWLEDGEMENT}

The work was supported by The Education Department of Anhui Province, the revitalization plan of comprehensive reform of professional pilot project, Project number: [2013zy088]; Teaching reform research project in Colleges and universities in Anhui Province, Project number: [2012jyxm591]; The Education Department of Anhui province to revitalize the experimental training center demonstration project, project number: [2013sxzx025]; Teaching reform research project in Colleges and universities in Anhui Province, Teaching reform research project in Colleges and universities in Anhui Province, Project number: [2013jyxm588]

\section{REFERENCES}

[1] Jun Zhao, Wanzheng Zeng. A study on the construction of class teaching evaluation index system in local universtiies. Teaching and Learning Research, 2013(6):4243.

[2] Mang Li, Minjun Cai. The construction and implementation of university teachers'class teaching evaluation index system. Modern Education Technology, 2013(5):36-38.

[3] Hua Liu. Developmental class teaching evaluation index system: ideas and examples. Global Education, 2013(3):48-55.

[4] Zhuqiang Xiao, Li Jie. A study on teaching quality evaluation index system of industrial designing centered as practicability. China Adult Education, 2010(17):133-134.

[5] Chunyan Zhang, Chunxia Zhang, Haixing Hu. A study on the system of practical training teaching quality evaluation index for vocational schools. Journal of Educational Institute of Jilin Province, 2014(3):112-113.

[6] Guangbin Zhang, Hongrui Meng, etc. Examples of JAVA course designing. Beijing: Tsinghua University press, 2007: 30-68.

[7] Songtao Yu, Zhenchen Xu, etc.SQL Server2005 Management and development of the database. Beijing: People's Posts and Telecommunications Press, 2001:1018. 